Bond University

Research Repository

\title{
The effectiveness of virtual and augmented reality in health sciences and medical anatomy
}

Moro, Christian; Štromberga, Zane; Raikos, Athanasios; Stirling, Allan

Published in:

Anatomical Sciences Education

DOI:

10.1002/ase. 1696

Licence:

Unspecified

Link to output in Bond University research repository.

Recommended citation(APA):

Moro, C., Stromberga, Z., Raikos, A., \& Stirling, A. (2017). The effectiveness of virtual and augmented reality in health sciences and medical anatomy. Anatomical Sciences Education, 10(6), 549-559.

https://doi.org/10.1002/ase.1696

\section{General rights}

Copyright and moral rights for the publications made accessible in the public portal are retained by the authors and/or other copyright owners and it is a condition of accessing publications that users recognise and abide by the legal requirements associated with these rights.

For more information, or if you believe that this document breaches copyright, please contact the Bond University research repository coordinator. 


\title{
The effectiveness of virtual and augmented reality in health science and medical anatomy
}

\author{
Authors: Christian Moro, Zane Štromberga, Athanasios Raikos, Allan Stirling
}

Affiliation: Faculty of Health Sciences and Medicine, Bond University, Gold Coast, 4229.

Note: This is a pre-proof version of this manuscript. The final version can be found at:

Wiley Online Library: http://onlinelibrary.wiley.com/doi/10.1002/ase.1696/full

DOI : 10.1002/ase.1696

To reference this article: Moro, C., Stromberga, Z., Raikos, A. and Stirling, A. (2017), The effectiveness of virtual and augmented reality in health sciences and medical anatomy. Anatomical Sciences Education. doi:10.1002/ase.1696

Correspondence to: Dr. Christian Moro, Faculty of Health Sciences and Medicine, Bond University, Gold Coast, QLD 4229, Australia. Telephone: +61 (0) 755954775.

E-mail: cmoro@bond.edu.au

Runninghead: VR and AR in health sciences and medical anatomy

Keywords: gross anatomy education; health sciences education; undergraduate education; medical education; virtual reality; augmented reality; mixed reality; computer-aided instruction; oculus rift; tablet applications 


\begin{abstract}
Although cadavers constitute the gold standard for teaching anatomy to medical and health science students, there are substantial financial, ethical and supervisory constraints on their use. In addition, although anatomy remains one of the fundamental areas of medical education, universities have decreased the hours allocated to teaching gross anatomy in favor of applied clinical work. The release of virtual (VR) and augmented reality (AR) devices allows learning to occur through hands-on immersive experiences. The aim of this research was to assess whether learning structural anatomy utilizing VR or AR is as effective as tabletbased (TB) applications, and whether these modes allowed enhanced student learning, engagement and performance. Participants $(n=59)$ were randomly allocated to one of the three learning modes: VR, AR or TB and completed a lesson on skull anatomy, after which they completed an anatomical knowledge assessment. Student perceptions of each learning mode and any adverse effects experienced were recorded. No significant differences were found between mean assessment scores in VR, AR or TB. During the lessons however, participants are more likely to exhibit adverse effects such as headaches (25\% in VR $P<$ 0.05 ), dizziness ( $40 \%$ in VR, $P<0.001$ ) or blurred vision (35\% in VR, $P<0.01$ ). Both VR and AR are as valuable for teaching anatomy as tablet devices, but also promote intrinsic benefits such as increased learner immersion and engagement. These outcomes show great promise for the effective use of virtual and augmented reality as means to supplement lesson content in anatomical education.
\end{abstract}

Keywords: Virtual Reality; Augmented Reality; Mixed Reality; Computer-aided instruction; Interactive Media in Education; Medical education; Oculus Rift; Tablet applications. 


\section{INTRODUCTION}

Educational technology is changing the way people engage and interact with learning material. Its goal is to create a powerful environment where the student can use their innate abilities of learning to grasp complex concepts and acquire knowledge through observation, imitation and participation (Goodyear and Retalis, 2010). Technology enhanced learning is most effective when it seamlessly integrates into the curriculum, mitigates the passive lecture experience and the large number of students in a class, and also provides a tool within which students can engage in meaningful experiences and gain knowledge (Garrison and Akyol, 2009). In response to technological advancements, a variety of multimedia information delivery tools have been developed and are currently in use to enhance students' learning outcomes. These supplementary materials include podcasts, screencasts and educational software available for use on a personal computer and mobile devices, such as smartphones and tablets (Scalise et al., 2011; Green et al., 2012; Molnar, 2016). The availability of multimedia technology, digital content and software empowers the modern-day students as it provides opportunities to engage with learning materials more easily and effectively. The consumer-grade release of new visualization technologies such as virtual reality through the Oculus Rift (Oculus VR, LLC., Menlo Park, CA) and Gear VR (Samsung Electronics Co., LTD., Suwon, South Korea) and augmented reality have paved a way to learn in a manner that previously not possible. For clarity, in this research study, the terms applied have been defined as follows:

- Virtual reality (VR): The user's senses (sight, hearing and motion) are fully immersed in a synthetic environment that mimics the properties of the real world through high resolution, high refresh rate head-mounted displays, stereo headphones and motion-tracking systems.

- Augmented reality (AR): Using a camera and screen (i.e. smartphone or tablet) digital models are superimposed into the real-world. The user is then able to interact with both the real and virtual elements of their surrounding environment.

- Three-dimensional (3D) tablet displays: Utilizing high-resolution screens on tablets and smartphones to visualize pseudo-3D models and environments. The user interacts with digital aspects on the screen and manipulates objects using a mouse or finger gestures.

\section{Current trends in health science education}

Medical and health science students must gain many skills and acquire vast arrays of knowledge throughout their time at university to become competent practitioners, with anatomy in particular being one of the cornerstones of health education. Without proper understanding of anatomy, regardless of the area of healthcare, practitioners can be unable to perform investigations effectively as they require knowledge of organs and tissues precise locations (Singh et al., 2015). Anatomy is traditionally taught at the beginning of a health science or medical course to provide the fundamental knowledge in four main areas: gross anatomy, neuroanatomy, histology and embryology (Turney, 2007). It is commonly delivered in the form of lectures, which include a slideshow presentation and a verbal description of the concepts, dissections and prosections, clinical cases and self-directed study using twodimensional (2D) images and multimedia resources (Murgitroyd et al., 2015).

The field of science is constantly evolving and with this comes an increase in topics that must be included within a modern curriculum, resulting in a paradigm shift in the way health is taught. Many health science course curricula utilize a problem-based learning framework which places a greater emphasis on student self-directed learning (Moro and McLean, 2017). 
This has led to less face to face teaching time in many of the 'basic sciences' and a greater dependence on supplementary materials and modules outside the formal course time (Johnson et al., 2012). Although anatomy remains an integral part of health science education, universities have decreased hours allocated to teaching anatomy and replaced them with applied clinical work. In 2009 the amount of time dedicated to teaching gross anatomy was found to have decreased by $55 \%$ over the span of the past 49 years within the medical curriculum in universities within the United States of America (Drake et al., 2002, 2009, 2014). Similarly, a study conducted in Australia and New Zealand, concluded that the time allocated for gross anatomy has also declined when compared to historical data (Craig et al., 2010), potentially impacting the foundational knowledge of doctors, nurses, dentists, biomedical and laboratory scientists, and other health science practitioners. A further decline in the time allocated to gross anatomy is apparent if no reforms are made to the current medical curricula (Singh et al., 2015). Based on the current situation, students in health science courses are expected to spend more time learning anatomy using supplementary resources as means of bridging the knowledge gaps.

\section{Supplements used to enhance anatomical education}

Anatomical learning is best done in a setting where desired structures can be examined from all angles. This includes examinations of actual structures using cadavers or synthetic recreations, such as silicone or plastic models. Surgeons stress the importance of dissections in anatomy teaching, as it provides an effective method for learning anatomical details, familiarizing the students with variations in human physiology and appreciating structures of the body that cannot be examined during an operation (Turney, 2007; Sheikh et al., 2016). On average, medical students can get approximately three hours of anatomy laboratory time each week where they share a cadaver between 10 - 12 students (Snelling et al., 2003). These sessions are tightly structured and in many universities, students are unable to gain access to the 'wet specimens' outside of scheduled times (Codd and Choudhury, 2011; Murgitroyd et al., 2015). This means that the students only have a limited window in which they can learn anatomy effectively from a cadaver. Students are then required to turn to supplementary materials to enhance their anatomical knowledge through self-directed study. This material most commonly consists of 2D supplementary resources such as lecture slides, textbooks and flashcards (Messier et al., 2016). An issue with learning from static images is that anatomical structures are three-dimensional and it can be difficult to comprehend spatial relationships between structures. 2D images also rely on the student's ability to transform these into 3D structures, which can be a challenging cognitive leap for those who find it difficult to visualize or mentally rotate anatomical structures (Marsh et al., 2008; Brewer et al., 2012). It also has to be noted that these static images, even if mentally rotated can only produce an image that is assumed by the learner, however it can be inaccurate as the mind is filling the gaps of the missing structures (Linn and Petersen, 1985; Liesefeld et al., 2015). With advances in educational technology these traditional resources can be supplemented by interactive multimedia learning tools (Walsh, 2014; Trelease, 2016) and interactive software that can be accompanied with both auditory and visual information (Taveira-Gomes et al., 2016).

For students, technology facilitates access to learning content at any time and place, whereas for educators it expands their educational impact by not constraining learning to classroom sessions (Goh, 2016). It also allows educators to guide students throughout self-directed learning sessions, which can be particularly important for undergraduate students who often require additional support compared to postgraduates (Moro and McLean, 2017). Multimedia tools use a combination of words and pictures (Mayer, 2009), such as with "screencasts" 
which are videos captured on a computer screen accompanied by an audio narration (Green et al., 2012) and commonly u sed as a replacement to lecture recordings (Dey et al., 2009) or tutorials (Lee et al., 2008). Although there have been several applications of screencasts and in medical education, such as with teaching embryology (Evans, 2011) and structural anatomy (Pickering, 2015), students have no control over the learning material other than the option to pause/play or rewind/forward the screencast. A review by Trelease, 2016, outlines how the development of 3D-simulation and modelling practices has stimulated the production of a wide range of learning modes that can increase the engagement of students in anatomical education, such as surgical simulations, viewing methods for regional anatomy, and 3D "virtual anatomy". Initial development of new software and educational content can be costly and time consuming, however, rapid distribution options now mean that only one original copy is necessary and all modifications can be immediately uploaded to each version (Goh, 2016). Therefore, the best way for educators to teach anatomy may be through combining multiple resources (plastic models, dissections and learning software) to achieve optimal results, as students benefit the most when a range of different learning modalities are available (Estai and Bunt, 2016).

\section{Applications of 3D interactive software to enhance anatomical education}

Whilst a cadaver is an effective resource due to its ability to display spatial information, textbooks are commonly used alongside the specimens in order to identify the names of features and how the anatomy links with physiology (Codd and Choudhury, 2011).

Dissections also have limitations in teaching various areas of the human body such as skeletal and nervous systems (Papa and Vaccarezza, 2013), whereas written resources are usually very content dense and contain more information than required for the level of study undertaken. Some advantages of 3D anatomical models in comparison to textbooks or traditional 2D learning modes include enhanced spatial understanding of the interrelationships between different body structures (Huang et al., 2010). It has been established that exploration of a virtual environment can help to develop spatial knowledge, with the representations being nearly as accurate as those being formed when exploring an object in real life (Dalgarno et al., 2002). Virtual learning tools may also reduce the performance gap that exists between those who struggle to visualize spatial structures and those confident in their spatial ability (Chen, 2006), and even assist overall comprehension by reducing the cognitive effort required when learning new anatomical contexts (Küçük et al., 2016). Additionally, 3D models are especially beneficial in cases where traditional methods of dissection may be limited in the ability to educate students on complex structures, such as the middle ear and the larynx (Nicholson et al., 2006; Nicholson et al., 2008; Hu et al., 2009). The use of 3D technology supplements may also provide a benefit to student long-term retention of gross anatomy (Peterson and Mlynarczyk, 2016), making it useful to supplement students traditional anatomical learning techniques with modern virtualization techniques and devices.

There are two types of virtual environments that can be used in education: a virtual world that mimics the real world (e.g. a virtual room) or a computer-generated 3D object (e.g. anatomical structures) (Lee and Wong, 2008). Users generally enjoy learning in a virtual environment as they are more curious to explore it. This results in heightened involvement and engagement (Chittaro and Ranon, 2007), alongside other beneficial variables, including motivation, presence, interactive experiences and ease of use (Lee and Wong, 2008). Battulga et al. (2012) found that students were more interested when spending time learning anatomical structures through a 3D model, and Foo et al. (2013) noted that students were 
more curious to explore the 3D model and spent more time looking for anatomical structures when compared to traditional 2D methods.

The potential for virtual reality to enhance anatomical education has been around for more than 40 years; however, it has not been widely available due to the associated high costs (Liu et al., 2016). Over the past twenty years, there have been dramatic advances in the virtual reality technology, including increases in computational speed, graphics rendering, tracking devices and user interfaces (Rizzo et al., 2014). These advances have created new opportunities for creating immersive educational experiences that previously were not possible. In 2016, after the release of two developer kits Oculu s Rift DK1 and DK2, the first consumer-grade Oculus Rift CV1 (Oculus VR, LLC., Menlo Park, CA) became available for the general public. Some examples of virtual reality applications within health science and medical education include: an examination of digital pathology slides using an Oculus Rift DK2 (Farahani et al., 2016); virtual drug design using gesture-recognition instead of standard input devices (Norrby et al., 2015); and a 3D virtual anatomy puzzle using Oculus Rift DK2 (Messier et al., 2016). The release of modern 3D virtual systems has paved the way for new approaches to medical imaging and education and have demonstrated success as beneficial supplements in anatomical education (Peterson and Mlynarczyk, 2016; Miller, 2016).

Another 3D model visualization technology that shows promise in facilitating meaningful learning experiences through strong visualization and manipulation is augmented reality (Kamphuis et al., 2014). Augmented reality superimposes digital models in the user's realworld through the use of a camera and a screen, where the user is able to interact with both the real and virtual elements of their surrounding environment (Azuma et al., 2001; Kirner et al., 2012). It enhances the student's interactions with the real world by projecting spatial information in the form of a virtual object that cannot be directly detected by their own senses (Azuma, 1997; Ellaway, 2010). When AR was first introduced, it was mainly used in professional contexts to aid in complex tasks; such as the assembly of equipment and medical surgeries (Barfield, 2015). It has also been used in image-guided surgery to visualize structures of the body that are not visible below the surface thus reducing the surgical time and increasing the precision of the procedure (Kersten-Oertel et al., 2013). The most commonly used hardware for AR are handheld devices like tablet or a smartphone (Kamphuis et al., 2014). Despite its potential, there has not been a widespread implementation of this technology in anatomical education, as the current studies are still focusing on the development and usability of AR as a learning tool (Wu et al., 2013). It is hypothesized that by implementing augmented reality as a supplement to traditional learning methods in anatomical education, the learning process would become more student-centered thereby allowing students to expand on information already obtained (Delello et al., 2015). What makes AR an excellent tool for implementation in anatomical education is that most people already own the devices required to run this technology, which makes AR cheap, readily accessible and not requiring specialized equipment for its use.

To our knowledge, the modern-day virtual or augmented reality systems have not yet been widely introduced in a university classroom setting. As such, this is an important area in technology-enhanced education to explore. There is no clear consensus in past research on the use of 3D models to enhance student learning outcomes (Azer and Azer, 2016). Despite the great potential, successful integration of 3D models in the medical curriculum is limited by a paucity of research, and thus lack of evidence demonstrating its effectiven ess. However, with the release of modern-day virtual and augmented reality, on which these models can be visualized, the learning experience can become more immersive. Although it has been 
established that students greatly enjoy learning on VR and AR (Hu et al., 2009; Hu et al., 2010; Keedy et al., 2011; Vuchkova et al., 2011), it is uncertain whether these tools provide a more effective method for gaining knowledge. Therefore, the purpose of this study is to compare the effectiveness of AR, VR and tablet-based applications in anatomical education.

\section{MATERIALS AND METHODS}

\section{Participants}

A total of 59 participants studying anatomy were recruited for this study with $84.7 \%$ percent $(\mathrm{n}=50)$ being students in biomedical and health sciences, $8.5 \%$ students in medicine $(\mathrm{n}=5)$, and $6.8 \%$ students from other Faculties $(n=4)$. This was run as a mixed-method triangulative study over a period of 12 months. Randomization was performed through https://www.random.org/ (Randomness and Integrity Services Ltd., Dublin, Ireland). All recruited participants completed the study and no data was withdrawn. Groups received an identical lesson presented in either VR, AR or on a tablet, which contained a computerized interactive 3D model of a skull and a 10-minute audio-stream narrated by a specialist surgeon. As different parts of the skull were introduced during the audio-stream, structures of interest would highlight in blue to draw the learner's attention. After the lesson, participants answered Likert-style questions regarding any adverse health effects experienced during the lesson through a questionnaire developed for assessing virtual reality viewing when using a head-mounted display (adapted from Ames et al., 2005). Participants also answered questions regarding their perceived engagement with the learning module (adapted from $\mathrm{Hu}$ et al., 2009). The last requirement for participants was the completion of a 20 question anatomy test to evaluate acquired knowledge developed by two clinical anatomists to question knowledge expected of a second-year anatomy student. Participant gender was distributed evenly, with an approximately neutral gender balance of $47 \%$ males and $53 \%$ females (Table 1). The mean age of participants was $20.7 \pm 5.5$ years old, ranging from 17 to 53 years. Through the process of randomization, 20 participants were allocated to the VR group, 17 to AR group and 22 participants to tablet device group. Research ethics was approved by the Bond University Human Ethics Research Committee, and all participants provided informed consent.

Table 1: Outline of participant demographics

\begin{tabular}{|l|l|l|l|l|}
\hline \multicolumn{1}{|c|}{ Characteristics } & \multicolumn{1}{|c|}{$\begin{array}{c}\text { Virtual reality } \\
(\mathbf{n = 2 0})\end{array}$} & $\begin{array}{c}\text { Augmented } \\
\text { reality }(\mathbf{n = 1 7})\end{array}$ & $\begin{array}{c}\text { Tablet device } \\
(\mathbf{n = 2 2})\end{array}$ & \multicolumn{1}{|c|}{$\begin{array}{c}\text { Total } \\
(\mathbf{N = 5 9 )}\end{array}$} \\
\hline Male, $\mathrm{n}(\%)$ & $8(40.0 \%)$ & $10(58.8)$ & $10(45.5)$ & $28(47.5)$ \\
\hline Female $(\mathrm{n})$ & $60 \%(12)$ & $41 \%(7)$ & $55 \%(12)$ & $53 \%(31)$ \\
\hline Age, mean $( \pm \mathrm{SD})$ & $20.2( \pm 3.5)$ & $19.5( \pm 2.3)$ & $22.2( \pm 8.0)$ & $20.7( \pm 5.5)$ \\
\hline $\begin{array}{l}\text { Has a science } \\
\text { background }(\mathrm{n})\end{array}$ & $60 \%(12)$ & $65 \%(11)$ & $64 \%(14)$ & $63 \%(37)$ \\
\hline $\begin{array}{l}\text { Previously studied } \\
\text { anatomy (n) }\end{array}$ & $50 \%(10)$ & $53 \%(9)$ & $59 \%(13)$ & $54 \%(32)$ \\
\hline
\end{tabular}

\section{Development of the application}

Applications for AR, VR and tablet were written using JavaScript within Unity v5 (Unity Technologies, San Francisco, CA). The Oculus Rift was run on an Alienware Area 51 with a CORE i7-5820 CPU @ 3.30GHz, 16GB RAM (Dell Inc. Round Rock, TX, USA) and 
GTX980ti GPU (nVidia, Santa Clara, CA, USA) with Windows 10 x64 operating system. Augmented reality was developed using the Vuforia v5 plug-in for Unity (PTC Inc., Boston, MA) and run on Samsung Galaxy Tab S2 (Samsung Electronics, Seocho District, Seoul, South Korea) devices. The application developed by the authors of this paper, was created in a way to be entirely interactive for the user. On the Oculus Rift, the object directly in front of the user became highlighted, and the name of the feature was presented on the screen. The left-click button engaged a "dissect" mode, removing the highlighted layer in front of the user, revealing the underlying structures. The right click button was "undo", restoring the removed layers. The middle mouse wheel allowed zooming in-and-out, and the middlemouse-button moved the camera to focus on the object was being viewed. Moving the mouse to the left or right orbited the focused structure. This allows the user to completely navigate the virtual model, removing and restoring layers at will, and viewing names for each individual feature through the movements of their head. On the AR and tablet apps, the dissect and undo modes were present as icons along the right hand side of the screen, along with a multi-select mode, audio start/stop, change object-focus and a "reset to default" option. When the user 'touched' on a feature of the model in the AR or tablet applications, the selected area highlighted and its name displayed on the screen. This highlighted object was then able to be removed. Two-finger touching of the screen allowed panning, while pinching finger gestures allowed the user to zoom in and out and navigate the model. The audio-stream was identical in all three modes, and when the clinical anatomist providing the voiceover lesson mentioned individual terms or features, that would highlight on the object in a lightblue color (e.g: the background highlighting of objects was synced with the audio to draw the users attention). During the audio, if the user had previously "dissected" or hidden the object being described, that section of the model would reappear prior to being highlighted. From this, the user could immediately follow the audio descriptions of the anatomical structures and view them as individually highlighted features.

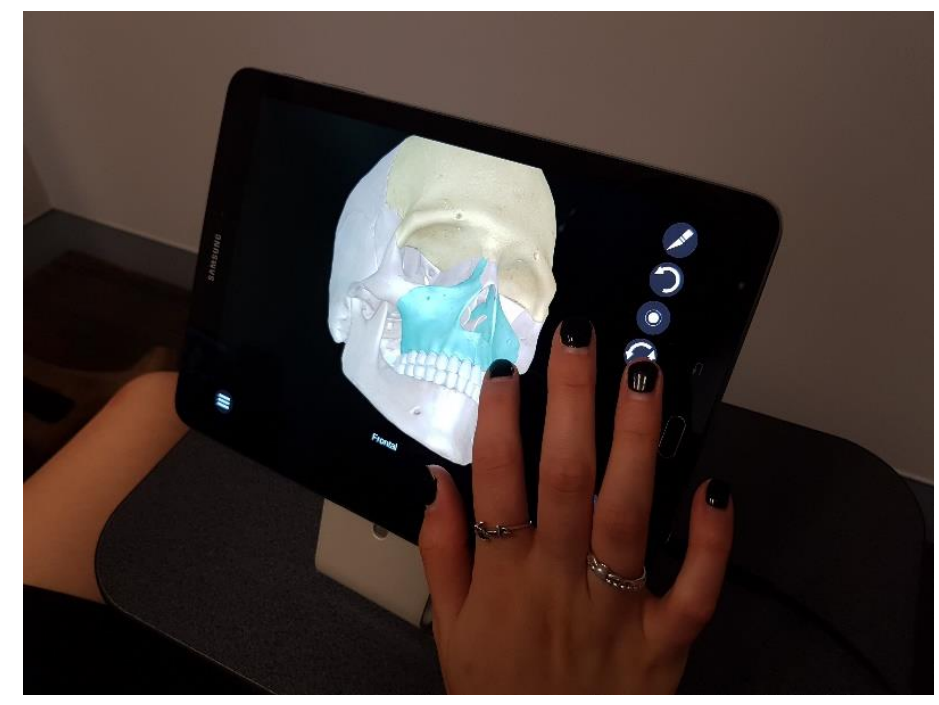

Analysis

A one-way ANOVA was used to evaluate the association between the mode of delivery (VR, AR or tablet) and the anatomy test scores. A Kruskal-Wallis H-test was used to evaluate the association between the mode of delivery and the adverse health effects exhibited during the lesson, as well as participant perception of the learning mode. For examinations between two variables, a Student's unpaired two-tailed $t$-test was applied. All statistics were completed using SPSS 24.0 (IBM Corporation, Amonk, New York). The adverse health effects were rated on a four-point Likert scale $(1=$ none to $4=$ severe $)$, where lower scores indicated less 
symptoms experienced. Participant perceptions were rated on a five-point Likert scale $(1=$ strongly disagree to $5=$ strongly agree), where lower scores indicated negative perceptions about the learning mode. At the completion of the online questionnaire, participants were provided with a sheet of questions regarding their learning experience and suggestions for future. The participants were able to expand on their experience and highlight the advantages and limitations of each learning tool. The 20-question A-E multiple-choice anatomical assessment was divided into two sections, a 10-question "factual" set which requested direct knowledge of regions or bones from text, e.g. the lateral part of the orbit is formed principally by which bone?". The remaining 10-questions were classed as "spatial questions", where an image of the skull presented with a bone or area highlighted, and the participant was asked questions such as: "which bone is highlighted in the picture above" (Table 2).

Table 2: Examples of the multiple-choice anatomy factual (\#1-3) and spatial (\#4) questions.

1. Which of the following is a paired bone that forms part of the viscerocranium (facial skeleton)?

2. Which bone of the skull contains the middle and inner portions of the ear?

3. The lateral part of the orbital margin is formed principally by which bone?
A. Mandible
B. Nasal
C. Occipital
D. Temporal
E. Vomer
A. Temporal
B. Parietal
C. Mandible
D. Maxilla
E. Vomer
A. Ethmoid
B. Occipital
C. Zygomatic
D. Sphenoid
E. Nasal

4. Which bone of the skull is highlighted in the image below?

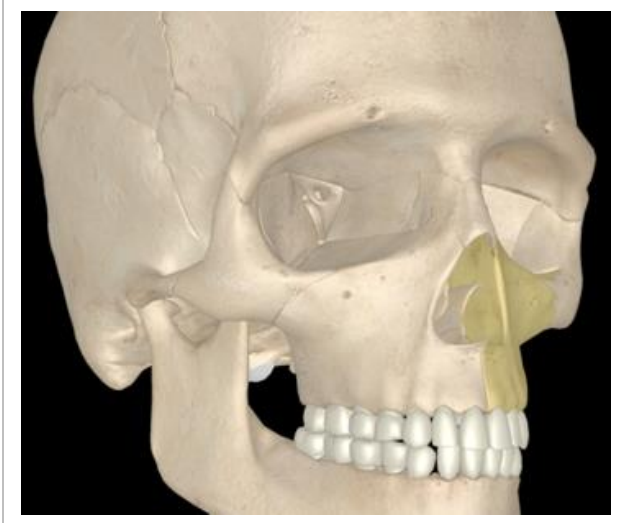
A. Maxilla
B. Nasal
C. Zygomatic
D. Mandible
E. Lacrimal 


\section{RESULTS}

\section{Participants}

Just over half of participants (54\%) reported having taken a subject in anatomy prior to the study, with the percentage ranging from $50 \%$ to $59 \%$ across the three study groups. $83 \%$ of participants stated that they had no prior knowledge on the skull anatomy, whereas 10 participants had previously studied skull anatomy and were confident that they still remembered the names of the individual structures. Most (74\%) participants had no previous experience with augmented or virtual reality prior to this study. The majority (95\%) of participants reported that they sometimes have difficulties understanding the position of an anatomical structure in 3D space while more than half (59\%) of participants reported having no prescribed glasses for either short-sightedness or long-sightedness.

\section{Results from the post-lesson anatomy knowledge test}

After completing a 10-minute lesson on skull anatomy utilizing either the VR, AR or a tablet, students were required to answer a 20 -question multiple-choice test. The VR group received a mean score of $64.5 \%$, the AR group received $62.5 \%$ and the tablet group received $66.5 \%$. There was no significant difference observed in anatomical test scores between the three groups ( $p=0.874$, Figure 1). Gender had no effect on participant scores ( $p=0.313)$, nor did having studied science since leaving high school $(\mathrm{p}=0.279)$, or declaring that they have difficulties understanding structure's position in space $(p=0.289)$.

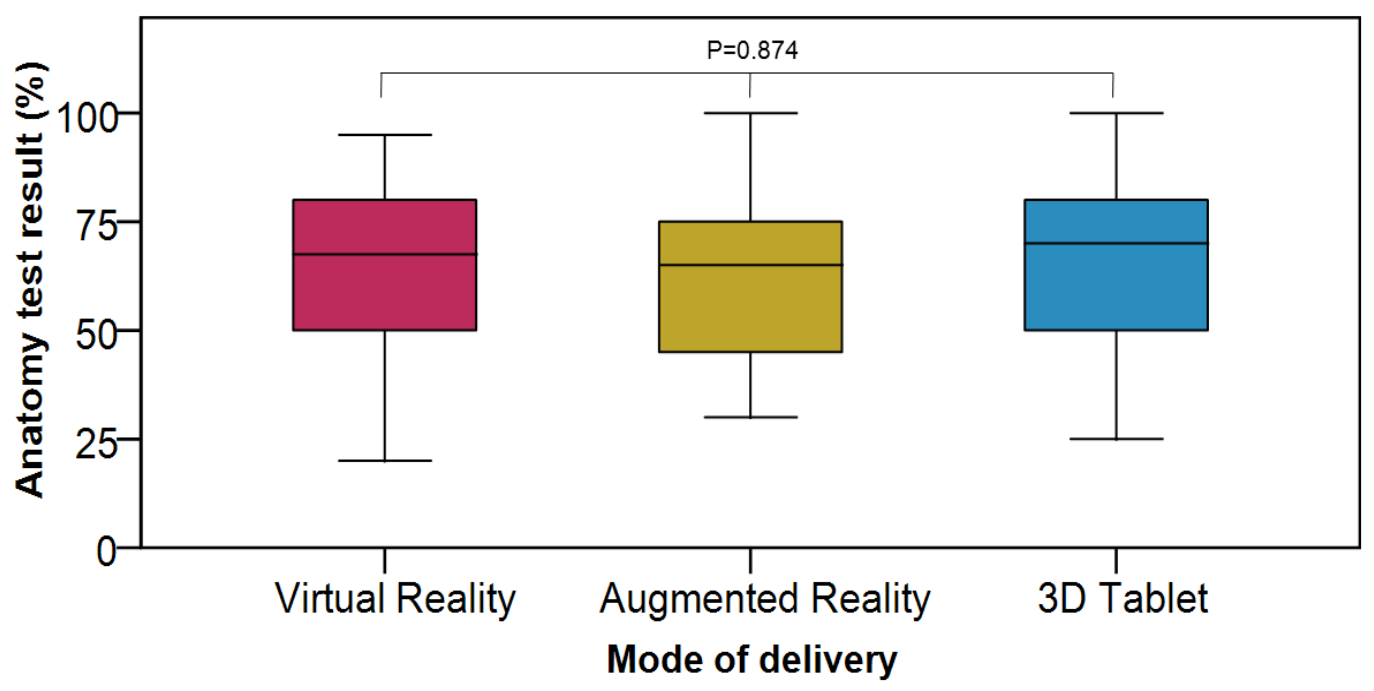

Figure 1: Boxplot of the overall mean scores achieved in the anatomical knowledge test (virtual reality $n=20$, augmented reality $n=17,3$ D tablet $n=22$; one-way ANOVA).

The VR group received a mean score of $59 \%$ in the factual component of the assessment and $70 \%$ in the spatial component. The augmented reality group scored 55\% in the factual recall component and $71 \%$ in the spatial anatomy component. Finally, the tablet group scored higher than the other two groups with a mean score of $61 \%$ in the factual component and $71 \%$ in the spatial component, however this increase was not significantly significant. All three groups performed better in the spatial recall questions having received a group mean 
score of $70.7 \%$ in comparison to $58.3 \%$ in factual recall questions (Figure 2). Overall, it was found that all three groups were equally capable of answering both factual $(p=0.623)$ and spatial $(p=0.933)$ questions with no significant differences observed in the mean scores between groups (Figure 2).
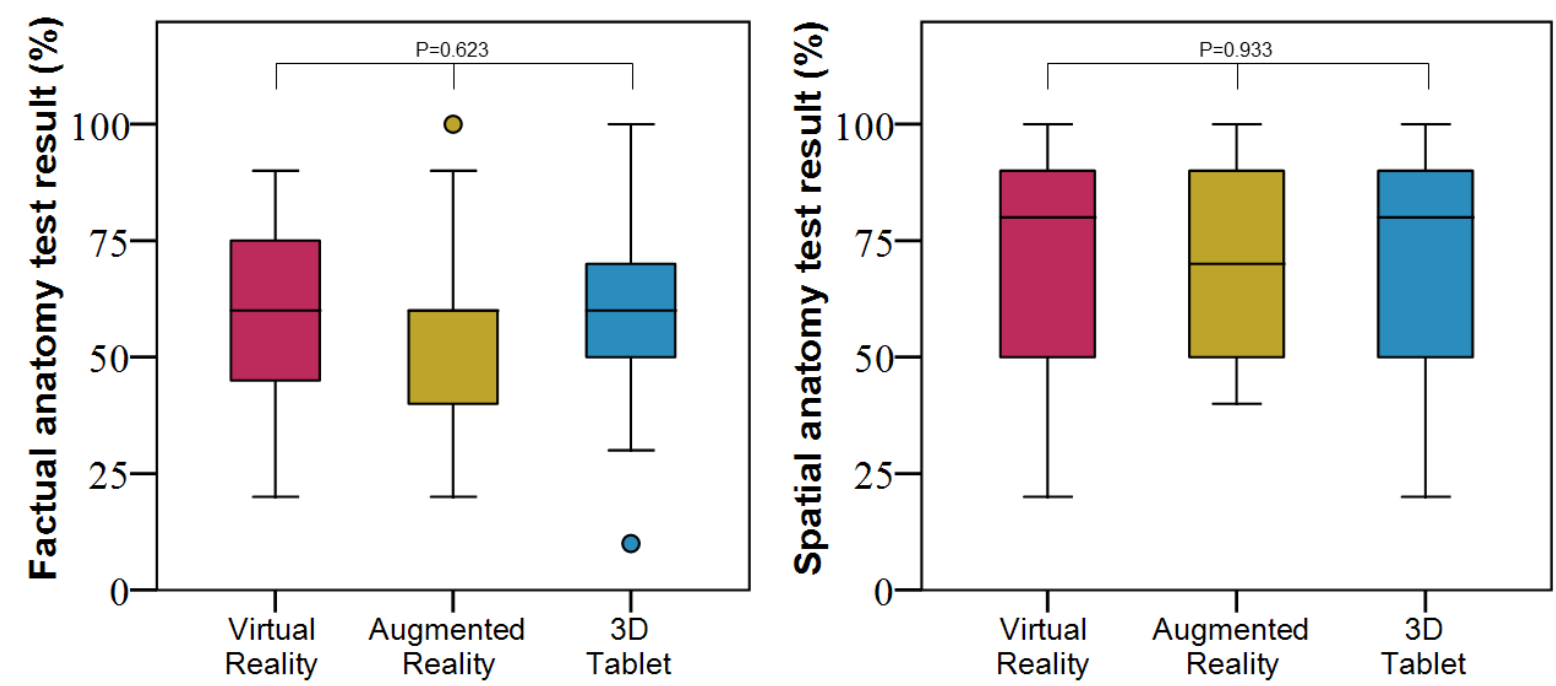

Figure 2: Boxplots of the mean scores achieved in the anatomical knowledge test for factual questions (Left) and spatial questions (Right) for each delivery mode (virtual reality $n=20$, augmented reality $n=17,3 \mathrm{D}$ tablet $n=22$; one-way ANOVA).

Several analyses were run in order to assess whether the variations in participant demographics had any influence on the responses to the anatomical assessment. Although the content presented in the lesson was new to most students, those who had previously taken a subject in anatomy had significantly higher test results ( score $=70 \%, \mathrm{n}=32$ ) than those new to learning names and anatomical features ( $\operatorname{score}=58 \%, \mathrm{n}=27, \mathrm{p}=0.029$, Student's $t$-test). Students that had studied the anatomy of the skull prior to the lesson did not perform significantly better than those with no prior knowledge $(p=0.228)$. Being enrolled in Year 1 physiology and anatomy course, was found to have no significant effect on the test scores ( $p$ $=0.263$ ). There was no significant difference between participants who reported adverse health effects and performance compared to those who were comfortable in the respective learning mode.

\section{Participant engagement with the learning modes}

Participants rated their learning experience highly in all seven domains across the three learning modes. There were no significant differences in mean scores observed for any of the seven statements among the three groups (Figure 3). Regarding the learning software, most (80\%) participants stated that they preferred to learn at their own pace rather than at a pace set by the educator and the audio-stream length (10 minutes) was agreed to be "appropriate" by $85 \%$ of the participants. Participants were also provided with a blank piece of paper, where they could volunteer responses and comments regarding their perceptions of the learning modes. These written responses were provided by 18 out of 20 VR participants, 16 of out 17 AR participants and 17 out of 22 tablet group participants. Examples of participant 
feedback from the VR group included: "The Oculus could be used as a good learning tool as it lets you see all the parts of the skull at whichever angle you want. Being able to visualize what we are learning in any way is helpful"; "Really good! Extremely helpful to visualize bones and to be able to see/choose which bones to look at. The audio was informative. I learned so much by doing this activity - definitely feel I learned a lot more doing this than learning from a lecture.".

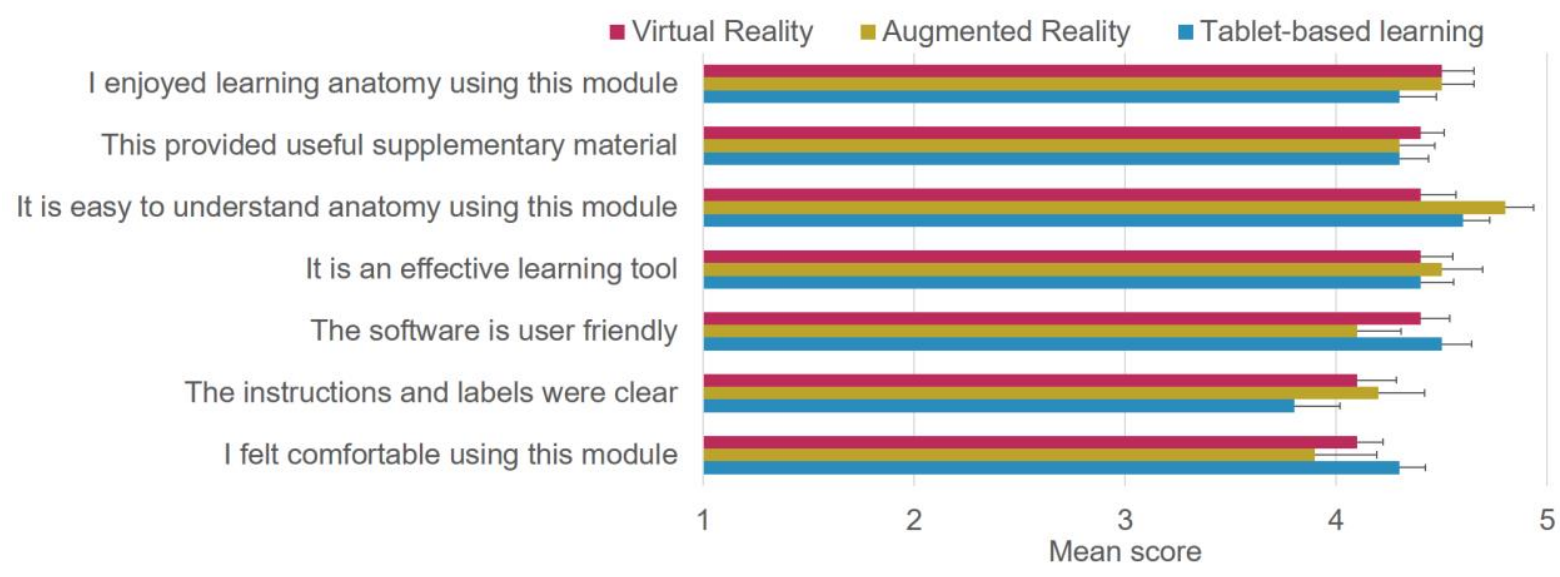

Figure 3: Student perceptions of the three learning modes (virtual reality $n=20$, augmented reality $n=17$, 3D tablet $n=22$; Mean \pm SEM).

\section{Adverse health effects exhibited during the lesson}

Among the three learning groups, participants reported different levels of adverse effects. The members in virtual reality group experienced significantly more symptoms than those in the augmented reality and 3D tablet groups. For the VR group, increases in adverse effects were recorded for general discomfort $(P=0.010)$, headache $(P=0.023)$, dizziness $(P=0.001)$, nausea $(P=0.016)$ and disorientation $(P=0.029$, Table 3$)$. For eye-related symptoms, the VR group experienced a significant increase in blurred vision $(P=0.003)$, difficulty focusing $(P=0.036)$ and double vision $(P=0.018$, Table 3$)$. In participant feedback, two written comments reported experiencing dizziness or even that the technology was distracting: " $I$ wasn't really paying attention to the audio stream. I was more intrigued by the technology, although it can get a little dizzy"; and "I did find that I became very distracted by how cool the program was that I realised I wasn't focusing on the learning aspect of it! Other than that, it is very cool and I can see this becoming a useful tool for anatomy students".

Table 3: Participants exhibiting adverse symptoms during the skull anatomy lesson on the virtual reality, augmented reality and tablet modes.

\begin{tabular}{|c|c|c|c|c|}
\hline General Symptoms & $\begin{array}{l}\text { Virtual Reality } \\
(\mathrm{n}=20)\end{array}$ & $\begin{array}{l}\text { Augmented } \\
\text { Reality }(\mathrm{n}=17)\end{array}$ & $\begin{array}{l}\text { Tablet device } \\
(\mathrm{n}=22)\end{array}$ & $p$ value \\
\hline General Discomfort & $8(40.0 \%)$ & $2(11.8 \%)$ & $1(4.5 \%)$ & $0.010^{*}$ \\
\hline Fatigue & $5(25.0 \%)$ & $2(11.8 \%)$ & $2(9.1 \%)$ & 0.304 \\
\hline Boredom & $6(30.0 \%)$ & $3(17.6 \%)$ & $9(40.9 \%)$ & 0.325 \\
\hline Drowsiness & $6(30.0 \%)$ & $1(5.9 \%)$ & $3(13.6 \%)$ & 0.125 \\
\hline Headache & $5(25.0 \%)$ & $1(5.9 \%)$ & $0(0.0 \%)$ & $0.023^{*}$ \\
\hline
\end{tabular}




\begin{tabular}{|l|l|l|l|l|}
\hline Dizziness & $8(40.0 \%)$ & $1(5.9 \%)$ & $0(0.0 \%)$ & $0.001^{*}$ \\
\hline Difficulty concentrating & $7(35.0 \%)$ & $8(47.1 \%)$ & $8(36.4 \%)$ & 0.803 \\
\hline Nausea & $4(20.0 \%)$ & $0(0.0 \%)$ & $0(0.0 \%)$ & $0.016^{*}$ \\
\hline Disorientation & $5(25.0 \%)$ & $0(0.0 \%)$ & $1(4.5 \%)$ & $0.029^{*}$ \\
\hline \multicolumn{5}{|l|}{ Eye-related Symptoms } \\
\multicolumn{5}{|l|}{$\mathrm{n}(\%)$} \\
Tired eyes & $5(25.0 \%)$ & $4(23.5 \%)$ & $2(9.1 \%)$ & 0.368 \\
\hline Sore/aching eyes & $1(5.0 \%)$ & $3(17.6 \%)$ & $2(9.1 \%)$ & 0.430 \\
\hline Eyestrain & $5(25.0 \%)$ & $2(11.8 \%)$ & $2(9.1 \%)$ & 0.379 \\
\hline Blurred vision & $7(35.0 \%)$ & $0(0.0 \%)$ & $1(4.5 \%)$ & $0.003^{*}$ \\
\hline Difficulty focusing & $6(30.0 \%)$ & $0(0.0 \%)$ & $2(9.1 \%)$ & $0.036^{*}$ \\
\hline Double-vision & $4(20.0 \%)$ & $0(0.0 \%)$ & $0(0.0 \%)$ & $0.018^{*}$ \\
\hline
\end{tabular}

Kruskal-Wallis H test: *p $<0.05$.

\section{DISCUSSION}

Although cadavers are most commonly used for teaching anatomy to medical and biomedical science students, there are substantial financial, ethical and supervisory constraints on their use (Turney, 2007). This means that alternative methods for learning spatial and theoretical concepts in anatomy have been researched considerably throughout the past decade.

However, very few of these ideas, such as QR codes (Kan et al., 2011, Traser et al., 2015), online applications (Petersson et al., 2009), 3D visual anatomical atlases such as Essential Anatomy (3D4Medical, 2016) or similar teaching aids have been demonstrated as effective for learning, or have been widely incorporated into university curricula. Virtual and augmented reality, however, present the first consumer-grade technology which can depict realistic 3D models and concepts to students, in a way that can be directed by a teacher or supervisor. The use of this technology has therefore generated considerable interest and its potential to supplement current teaching in anatomical education is exciting to both students and curricula developers alike. This study aimed to identify the effectiveness of migrating lessons otherwise taught in a lecture-format or alongside cadavers, into three separate modes. Although it has previously been established that tablet-based 3D applications could provide useful supplementary tools for students (Lewis et al., 2014), the learning outcomes when using AR and VR devices remain unclear. As both VR and AR offer heightened intrinsic benefits to the student: such as enhanced engagement; virtual environments and 3D-spatial visualizations of models; there was the risk of this novel technology being overly distracting or difficult to use by the student, and it was not clear whether students learning from VR or AR would achieve the same results, or even better results, than those using a tablet. However, the results showed that all three modes of learning were equally effective in teaching anatomy, and there were no significant differences between the students' mean scores. This outcome shows great promise for the effectiveness of virtual and augmented reality in the supplementation of lesson content in anatomical education.

Most students found that they enjoyed learning anatomy using the modules provided in this report. This desire to learn using interactive media is becoming a common theme, such as in one study where $3 \mathrm{D}$ oral radiographs were interpreted through a desktop application, and although student performance did not improve, the majority (88\%) of participants stated that they would prefer using 3D software instead of a textbook (Vuchkova et al., 2011). Another study on dental morphology determined that that 3D interactive media was just as effective as 
the traditional course with classroom lectures (Maggio et al., 2012), although student results were not necessarily increased. Specific to anatomical education using 3D interactive software, studies by Hu and colleagues (2009) on laryngeal anatomy and Keedy and colleagues (2011) on hepatobiliary anatomy also observed no increase in test scores when compared to standard written instruction group and a majority of participants reported high satisfaction rates. Similar to these listed studies, the enhanced engagement, enjoyment and participation observed in the VR and AR groups did not necessarily result in increased test scores. Some possible explanations for this may be may be due to the "novelty effect" as this technology has only recently been made available for the general to purchase rarely used in education and there were several reports in the written feedback of participants perceiving VR technology as "cool". Participants reported having spent more time getting familiar with the technology rather than listening to the audio-stream and learning the structures of the skull. However, as students become more accustomed to these virtual devices and applications, their comprehension of the content within is likely to increase, and modern packaged applications utilizing AR showing promising results for student engagement and learning, such as the ARBOOK (Ferrer-Torregrosa et al., 2015) and HuMAR prototype applications (Jamali et al., 2015) and it will be interesting to see the influence on students if these types of applications are implemented in medical and biomedical programs.

\section{Adverse health effects}

A potential issue that can have an impact on the learning experience and assessment results when using virtual reality is cybersickness, which causes nausea, disorientation, discomfort, headache, fatigue, difficulty concentrating and problems with vision (Rebenitsch and Owen, 2016). It is believed that cybersickness is due to a sensory mismatch, which happens when the visual system tells the body that is moving while the vestibular system tells the body it is stationary (Howarth and Costello, 1997). There have been previous reports on symptoms associated with cybersickness exhibited when using virtual reality in past studies (Mosadeghi et al., 2016). In this study, participants in the VR groups experienced significantly more symptoms than those in AR and tablet groups. The general symptoms exhibited (general discomfort, headache, dizziness, nausea and disorientation) are consistent with the symptoms caused by cybersickness with the use of head-mounted displays (Rebenitsch and Owen, 2016). Both general discomfort and dizziness was observed in $40 \%$ of participants in the first study, which is of concern as experiencing these symptoms would have a great impact on the learning quality and therefore make the student less immersed in the lesson. One-third of VR group experienced blurred vision and difficulty concentrating, whereas double-vision was present in $21 \%$ of participants. The prevalence of these symptoms was significantly higher in VR group in comparison to AR and tablet groups. Based on student feedback across all three studies, dizziness was a frequent symptom mentioned in the comments.

A relatively large portion of students reported "difficulty concentrating" across all three learning modes. Learning the large number of features and names of a new anatomical region all-at-once in an application may require processing demands that exceed the students' cognitive capabilities. The cognitive load theory, developed by Sweller (1994), emphasizes the limitations of human working memory when exposed to different instructional designs. A person is only able to process three to five "chunks of information" at the same time, therefore anything that exceeds simple cognitive activities may overwhelm the working memory and one's cognitive resources (Cowan, 2010). This would suggest that a student who learns in a complex virtual environment may have a large working load, which would then have an impact on the learning outcomes, especially for novice learners who have not been exposed to the content beforehand (Kirschner et al., 2006). As such, when creating an instructional tool, limits of the working memory and cognitive processing may need to be 
taken into consideration (Mayer, 2009). Study material containing a lot of elements will require a greater capacity of working memory to process the information simultaneously. In contrast, when using study material that contains a low number of interactive elements, the working memory is not as strained and all information could be learned serial manner without overwhelming the student (Sweller et al., 1998).

\section{Limitations and further studies}

This study was limited in its focus on the effectiveness of educating a relatively limited number of students studying introductory anatomy. A greater number of participants, from a wider cohort of students would further support the overall conclusions in this area. In particular, further interest would be in the influence of these teaching tools in educating medical graduates, or postgraduate students in more advanced anatomical concepts and features. This area of research would also benefit from further research into the adverse effects exhibited in this study, and potential methods that could be employed to minimize or reduce these in virtual and augmented anatomical education applications. Sample demographics may also have played a role in the study outcome, as it was determined that participants that had previously taken a course in anatomy received higher mean score in the anatomical test than those that had not. It is likely that people who have some degree of experience learning anatomy are more familiar with the terms and have a set system for learning structures, therefore leading to better results regardless of learning mode used. Finally, future studies could also provide benefit by identifying the optimal timeframe of lessons within VR and AR. This study utilized 10-minute sessions, however, it may be more comfortable for participants to spend longer or shorter periods within the virtual world, or even obtain a pre-exposure to the virtual environment for some time prior to the lessons. In order to provide optimal lessons, the differences in session lengths could be explored and refined to maximize learning.

\section{CONCLUSION}

Although cadavers constitute the gold standard for teaching anatomy to medical and biomedical science students, previous benefits have also been reported through the use of tablet-based software. However, modern advances in consumer-grade technology has allowed the creation of immersive $3 \mathrm{D}$ environments using virtual and augmented reality. This article presents both VR and AR as effective teaching tools, where student learning is as successful as with tablet-based applications although educators should be cautious regarding the introduction of adverse effects, such as blurred-vision and disorientation with VR in particular. However, both VR and AR provide additional intrinsic benefits, such as increased student engagement, interactivity and enjoyment. This finding shows great promise for future applications utilizing VR and AR, which are expected to become unique and powerful learning tools within health sciences and medical curricula. 


\section{NOTES ON CONTRIBUTORS:}

CHRISTIAN MORO, B.Sc., B.Ed., M.Bus., Ph.D., is an Assistant Professor and the Scientist and Scholar Theme Lead for the Medical Program at Bond University, Gold Coast, Australia. Christian teaches both medical and biomedical sciences, and his laboratory research interests include the physiology associated with diseases of the urinary bladder, while his medical education research focusses on the implementation of novel technological tools to enhance student learning, participation and interaction.

ZANE ŠTROMBERGA B.BiomSci. (Hon.) is a graduate (Ph.D.) student in Physiology and Pharmacology in the Faculty of Health Sciences and Medicine at Bond University, Gold Coast, Queensland, Australia. Her research interests involve urological functional studies and medical education.

ATHANASIOS RAIKOS, M.D., M.Clin.Educ., Ph.D., is an Assistant Professor of anatomy and the Year 2 Lead for the Faculty of Health Sciences and Medicine at Bond University, Gold Coast, Queensland, Australia. He teaches anatomy, histology, and embryology to medical and biomedical students and his research interest is in virtual and augmented reality technologies and their usefulness in medical and allied health education.

ALLAN STIRLING, M.B.Ch.B., M.R.C.S., M.Clin.Educ., is an Associate Professor of anatomy and histology and the Anatomy Lead for the Faculty of Health Sciences and Medicine at Bond University, Gold Coast, Queensland, Australia. Allan teaches clinical anatomy to medical and undergraduate science students and is passionate about using technology in his teaching to stimulate curiosity in his learners. 


\section{LITERATURE CITED:}

3D4Medical. 2016. Essential Anatomy 5. iPad, iPhone, iPod touch versions of anatomy apps. Version 5.03. San Diego, CA: 3D4Medical.com, LLC. Size 844 MB.

Ames SL, Wolffsohn JS, McBrien NA. 2005. The development of a symptom questionnaire for assessing virtual reality viewing using a head-mounted display. Optom Vis Sci 82:168176.

Azer SA, Azer S. 2016. 3D anatomy models and impact on learning: A review of the quality of the literature. Health Prof Educ 2:80-98.

Azuma R, Baillot Y, Behringer R, Feiner S, Julier S, MacIntyre B. 2001. Recent advances in augmented reality. IEEE Comput Graph Appl 21:34-47.

Azuma RT. 1997. A survey of augmented reality. Presence Teleoperat Virt Environ 6:355385.

Barfield W (Editor). 2015. Fundamentals of Wearable Computers and Augmented Reality. $2^{\text {nd }}$ Ed. Boca Raton, FL: CRC Press. 739 p.

Battulga B, Konishi T, Tamura Y, Moriguchi H. 2012. The effectiveness of an interactive 3 dimensional computer graphics model for medical education. Interact J Med Res 1:e2.

Brewer DN, Wilson TD, Eagleson R, de Ribaupierre S. 2012. Evaluation of neuroanatomical training using a 3D visual reality model. Stud Health Technol Inform 173:85-91.

Chen CJ. 2006. The design, development and evaluation of a virtual reality based learning environment. Australas J Educ Tech 22:39-63.

Chittaro L, Ranon R. 2007. Web3D technologies in learning, education and training: Motivations, issues, opportunities. Comput Educ 49:3-18.

Codd AM, Choudhury B. 2011. Virtual reality anatomy: is it comparable with traditional methods in the teaching of human forearm musculoskeletal anatomy? Anat Sci Educ 4:119125.

Cowan N. 2010. The magical mystery four: How is working memory capacity limited, and why? Curr Dir Psychol Sci 19:51-57.

Craig S, Tait N, Boers D, McAndrew D. 2010. Review of anatomy education in Australian and New Zealand medical schools. ANZ J Surg 80:212-216.

Dalgarno B, Hedberg J, Harper B. 2002. The contribution of 3D environments to conceptual understanding. In: Proceedings of the 19th Annual Conference of the Australasian Society for Computers in Learning in Tertiary Education (ASCILITE 2002): Winds of Change in the Sea of Learning Auckland; New Zealand, 2002 December 8-11. Volume 1, p 149-158. Australasian Society for Computers in Learning in Tertiary Education: Figtree, NSW, Australia. 
Delello JA, McWhorter RR, Camp KM. 2015. Integrating augmented reality in higher education: A multidisciplinary study of student perceptions. J Educ Multimedia Hypermedia 24:209-233.

Dey EL, Burn HE, Gerdes D. 2009. Bringing the classroom to the web: Effects of using new technologies to capture and deliver lectures. Res High Educ 50:377-393.

Drake RL, Lowrie DJ Jr., Prewitt CM. 2002. Survey of gross anatomy, microscopic anatomy, neuroscience, and embryology courses in medical school curricula in the United States. Anat $\operatorname{Rec} 269: 118-122$.

Drake RL, McBride JM, Lachman N, Pawlina W. 2009. Medical education in the anatomical sciences: The winds of change continue to blow. Anat Sci Educ 2:253-259.

Drake RL, McBride JM, Pawlina W. 2014. An update on the status of anatomical sciences education in United States medical schools. Anat Sci Educ 7:321-325.

Ellaway R. 2010. eMedical teacher. Med Teach 32:791-793.

Estai M, Bunt S. 2016. Best teaching practices in anatomy education: A critical review. Ann Anat 208:151-157.

Evans DJ. 2011. Using embryology screencasts: A useful addition to the student learning experience? Anat Sci Educ 4:57-63.

Farahani N, Post R, Duboy J, Ahmed I, Kolowitz BJ, Krinchai T, Monaco SE, Fine JL, Hartman DJ, Pantanowitz L. 2016. Exploring virtual reality technology and the oculus rift for the examination of digital pathology slides. J Pathol Inform 7:22-22.

Ferrer-Torregrosa J, Torralba J, Jimenez MA, Garcia S, Barcia JM. 2015. ARBOOK: Development and assessment of a tool based on augmented reality for anatomy. J Sci Educ Tech 24:119-124.

Foo JL, Martinez-Escobar M, Juhnke B, Cassidy K, Hisley K, Lobe T, Winer E. 2013. Evaluating mental workload of two-dimensional and three-dimensional visualization for anatomical structure localization. J Laparoendosc Adv Surg Tech A 23:65-70.

Garrison DR, Akyol Z. 2009. Role of instructional technology in the transformation of higher education. J Comput High Educ 21:19-30.

Goh PS. 2016. eLearning or technology enhanced learning in medical education-Hope, not hype. Med Teach 38:957-958.

Goodyear P, Retalis S (Editors). 2010. Technology-Enhanced Learning. ${ }^{\text {st }}$ Ed. Rotterdam, The Netherlands: Sense Publishers. 330 p.

Green KR, Pinder-Grover T, Millunchick JM. 2012. Impact of screencast technology: connecting the perception of usefulness and the reality of performance. J Eng Educ 101:717737. 
Howarth PA, Costello PJ. 1997. The occurrence of virtual simulation sickness symptoms when an HMD was used as a personal viewing system. Displays 18:107-116.

Hu A, Wilson T, Ladak H, Haase P, Doyle P, Fung K. 2010. Evaluation of a threedimensional educational computer model of the larynx: voicing a new direction. $\mathrm{J}$ Otolaryngol Head Neck Surg 39:315-322.

Hu A, Wilson T, Ladak H, Haase P, Fung K. 2009. Three-dimensional educational computer model of the larynx: Voicing a new direction. Arch Otolaryngol Head Neck Surg 135:677681.

Huang H-M, Rauch U, Liaw S-S. 2010. Investigating learners' attitudes toward virtual reality learning environments: Based on a constructivist approach. Comput Educ 55:1171-1182.

Jamali SS, Shiratuddin MF, Wong KW, Oskam CL. 2015. Utilising mobile-augmented reality for learning human anatomy. Procedia Soc Behav Sci 197:659-668.

Johnson EO, Charchanti AV, Troupis TG. 2012. Modernization of an anatomy class: From conceptualization to implementation. A case for integrated multimodal-multidisciplinary teaching. Anat Sci Educ 5:354-366.

Kamphuis C, Barsom E, Schijven M, Christoph N. 2014. Augmented reality in medical education? Perspect Med Educ 3:300-311.

Kan T-W, Teng C-H, Chen MY. 2011. QR code based augmented reality applications. In: Furht B (Editor). Handbook of Augmented Reality. ${ }^{\text {st }}$ Ed. New York, NY: Springer Science+Business Media, LCC. p 339-354.

Keedy AW, Durack JC, Sandhu P, Chen EM, O'Sullivan PS, Breiman RS. 2011. Comparison of traditional methods with 3D computer models in the instruction of hepatobiliary anatomy. Anat Sci Educ 4:84-91.

Kersten-Oertel M, Jannin P, Collins DL. 2013. The state of the art of visualization in mixed reality image guided surgery. Comput Med Imaging Graph 37:98-112.

Kirner C, Cerqueira CS, Kirner TG. 2012. Using augmented reality artifacts in education and cognitive rehabilitation. In: Eichenberg C (Editor). Virtual Reality in Psychological, Medical and Pedagogical Applications. ${ }^{\text {st }}$ Ed. Rijeka, Croatia: InTech d.o.o. p 247-270.

Kirschner PA, Sweller J, Clark RE. 2006. Why minimal guidance during instruction does not work: An analysis of the failure of constructivist, discovery, problem-based, experiential, and inquiry-based teaching. Educ Psychol 41:75-86.

Küçük S, Kapakin S, Göktaş Y. 2016. Learning anatomy via mobile augmented reality: Effects on achievement and cognitive load . Anat Sci Educ 9:411-421.

Lee EA-L, Wong KW. 2008. A review of using virtual reality for learning. In: Pan Z, Cheok AD, Müller W (Editors). Transactions on Edutainment I. $1^{\text {st }}$ Ed. Berlin, Germany: SpringerVerlag. p 231-241. 
Lee MJ, Pradhan S, Dalgamo B. 2008. The effectiveness of screencasts and cognitive tools as scaffolding for novice object-oriented programmers. J Inform Tech Educ 7:61-80.

Lewis TL, Burnett B, Tunstall RG, Abrahams PH. 2014. Complementing anatomy education using three-dimensional anatomy mobile software applications on tablet computers. Clin Anat 27:313-320.

Liesefeld HR, Fu X, Zimmer HD. 2015. Fast and careless or careful and slow? Apparent holistic processing in mental rotation is explained by speed-accuracy trade-offs. J Exp Psychol Learn Mem Cognit 41:1140-1151.

Linn MC, Petersen AC. 1985. Emergence and characterization of sex differences in spatial ability: A meta-analysis. Child Dev 56:1479-1498.

Liu M, Su S, Liu S, Harron J, Fickert C, Sherman B. 2016. Exploring 3D immersive and interactive technology for designing educational learning experiences. In: Neto FMM, de Souza R, Gomes AS (Editors). Handbook of Research on 3-D Virtual Environments and Hypermedia for Ubiquitous Learning. ${ }^{\text {st }}$ Ed. Hershey, PA: IGI Global. p 243-261.

Maggio MP, Hariton-Gross K, Gluch J. 2012. The use of independent, interactive media for education in dental morphology. J Dent Educ 76:1497-1511.

Marsh KR, Giffin BF, Lowrie DJ Jr. 2008. Medical student retention of embryonic development: Impact of the dimensions added by multimedia tutorials. Anat Sci Educ 1:252257.

Mayer RE. 2009. Multimedia Learning. $2^{\text {nd }}$ Ed. New York, NY: Cambridge University Press. $318 \mathrm{p}$.

Messier E, Wilcox J, Dawson-Elli A, Diaz G, Linte CA. 2016. An interactive 3D virtual anatomy puzzle for learning and simulation - Initial demonstration and evaluation. Stud Health Technol Inform 220:233-240.

Miller, M. 2016. Use of computer-aided holographic models improves performance in a cadaver dissection-based course in gross anatomy. Clin Anat. 29:917-924

Molnar A. 2016. Content type and perceived multimedia quality in mobile learning. Multimed Tools Appl (in press; doi: 10.1007/s11042-016-4062-2).

Mosadeghi S, Reid WM, Martinez B, Rosen TB, Spiegel BM. 2016. Feasibility of an immersive virtual reality intervention for hospitalized patients: An observational cohort study. JMIR Ment Health 3:e28.

Murgitroyd E, Madurska M, Gonzalez J, Watson A. 2015. 3D digital anatomy modelling Practical or pretty? Surgeon 13:177-180.

Moro C, McLean M. 2017. Supporting Students' Transition to University and Problem-Based Learning. Med Sci Ed pp1-9. doi:10.1007/s40670-017-0384-6 
Nicholson DT, Chalk C, Funnell WR, Daniel SJ. 2006. Can virtual reality improve anatomy education? A randomized controlled study of a computer-generated three-dimensional anatomical ear model. Med Educ 40:1081-1087.

Nicholson DT, Chalk C, Funnell WR, Daniel SJ. 2008. The evidence for virtual reality. Med Educ 42:224.

Norrby M, Grebner C, Eriksson J, Bostrom J. 2015. Molecular rift: Virtual reality for drug designers. J Chem Inform Model 55:2475-2484.

Papa V, Vaccarezza M. 2013. Teaching anatomy in the XXI century: New aspects and pitfalls. Sci World J 2013:310348.

Peterson DC, Mlynarczyk GS. 2016. Analysis of traditional versus three-dimensional augmented curriculum on anatomical learning outcome measures. Anat Sci Educ 9:529-536.

Petersson H, Sinkvist D, Wang C, Smedby Ö. 2009. Web-based interactive 3D visualization as a tool for improved anatomy learning. Anat Sci Educ 2:61-68.

Pickering JD. 2015. Anatomy drawing screencasts: Enabling flexible learning for medical students. Anat Sci Educ 8:249-257.

Rebenitsch L, Owen C. 2016. Review on cybersickness in applications and visual displays. Virtual Reality 20:101-125.

Rizzo A, Hartholt A, Grimani M, Leeds A, Liewer M. 2014. Virtual reality exposure therapy for combat-related posttraumatic stress disorder. Computer 47:31-37.

Scalise K, Timms M, Moorjani A, Clark L, Holtermann K, Irvin PS. 2011. Student learning in science simulations: Design features that promote learning gains. J Res Sci Teach 48:1050-1078.

Sheikh AH, Barry DS, Gutierrez H, Cryan JF, O'Keeffe GW. 2016. Cadaveric anatomy in the future of medical education: What is the surgeons view? Anat Sci Educ 9:203-208.

Singh R, Shane Tubbs R, Gupta K, Singh M, Jones DG, Kumar R. 2015. Is the decline of human anatomy hazardous to medical education/profession?--A review. Surg Radiol Anat $37: 1257-1265$.

Snelling J, Sahai A, Ellis H. 2003. Attitudes of medical and dental students to dissection. Clin Anat 16:165-172.

Sweller J. 1994. Cognitive load theory, learning difficulty, and instructional design. Learn Instruct 4:295-312.

Sweller J, Van Merrienboer JJ, Paas FG. 1998. Cognitive architecture and instru ctional design. Educ Psychol Rev 10:251-296. 
Taveira-Gomes T, Ferreira P, Taveira-Gomes I, Severo M, Ferreira MA. 2016. What are we looking for in computer-based learning interventions in medical education? a systematic review. J Med Internet Res 18:e204.

Traser CJ, Hoffman LA, Seifert MF, Wilson AB. 2015. Investigating the use of quick response codes in the gross anatomy laboratory. Anat Sci Educ 8:421-428.

Trelease RB. 2016. From chalkboard, slides, and paper to e-learning: How computing technologies have transformed anatomical sciences education. Anat Sci Educ 9:583-602.

Turney BW. 2007. Anatomy in a modern medical curriculum. Ann R Coll Surg Engl 89:104107.

Vuchkova J, Maybury TS, Farah CS. 2011. Testing the educational potential of 3D visualization software in oral radiographic interpretation. J Dent Educ 75:1417-1425.

Walsh K. 2014. The future of e-learning in healthcare professional education: Some possible directions. Ann Ist Super Sanità 50:309-310.

Wu H-K, Lee SW-Y, Chang H-Y, Liang J-C. 2013. Current status, opportunities and challenges of augmented reality in education. Comput Educ 62:41-49. 